\title{
A influência do uso e ocupação do solo na análise das variáveis limnológicas no ponto de monitoramento Stan 02700 do Rio Santo Anastácio, município de Piquerobi -SP
}

The influence of the use and occupation of the soil in the analysis limnological variables at the point of monitoring Stan 02700 of Santo Anastácio river, Piquerobi municipalality-SP

La infleunzia del uso y ocupacion del solo en las analyses de las variables en el punto de monitoramiento Stan 02700 del Rio Santo Anastácio, municipio de Piquerobi-SP

Fabio Eduardo Aznar Mestrando em Geografia, UNESP, Brasil fabio_aznar@hotmail.com

Luciane Maria dos Santos Mestranda em Ciências, UNESP, Brasil luciane-msantos@hotmail.com

Marcos Rogério Rodrigues da Silva Mestrando em Ciências, UNESP,Brasil marcos.silva857@etec.sp.gov.br

Renata Ribeiro de Araújo Doutora, Profa. Assistente, UNESP ,Brasil renata.r.araujo@unesp.br 


\begin{abstract}
RESUMO
No cenário preocupante da degradação dos recursos hídricos, é necessário encontrar mecanismos que auxiliem na conservação e recuperação de ambientes naturais degradados, e para isso a utilização de técnicas de avaliação e monitoramento ambiental, torna-se imprescindível. Para o presente artigo, a área selecionada para estudo foi o ponto de monitoramento da CETESB (Companhia Ambiental do Estado de São Paulo) - STAN 02700, na ponte do Rio Santo Anastácio, Rodovia SP 563, sendo esta uma área com disponibilidade de dados limnológicos realizados pela CETESB, e por ser uma região com histórico de uso e ocupação do solo pela monocultura da cana de açúcar, recebendo ainda efluentes sem tratamento. $O$ estudo visou a análise comparativa das variáveis limnológicas obtidas no ponto de monitoramento, de maneira sazonal nos meses de fevereiro, abril, junho, agosto, outubro e dezembro, entre os anos de 2015 à 2017, disponibilizadas pela CETESB com os valores de referência da resolução CONAMA $357 / 05$, verificando a qualidade do curso de água em questão. Após a realização dos valores disponíveis pela Companhia, foram selecionados os parâmetros (demanda bioquímica de oxigênio, ferro dissolvido, fósforo total, turbidez e Escherichia Coli), por apresentarem valores que estão em desconformidade com a classificação como rio de classe 2 que o mesmo recebe, independentemente do período estudado (2015-2017), valores estes acima do limite aceitável devido à influência da monocultura na região (turbidez), despejo de efluentes sem tratamento (DBO, Escherichia Coli, oxigênio dissolvido, fósforo total e ferro dissolvido, este último podendo ainda ser alterado pela composição do solo local)
\end{abstract}

PALAVRAS-CHAVE: Recursos Hídricos. Uso e Ocupação do Solo. Rio Santo Anastácio. Variáveis Limnológicas.

\title{
ABSTRACT
}

In the worrying scenario of water resources degradation, it is necessary to find mechanisms that help in the conservation and recovery of degraded natural environments, and for that the use of environmental assessment and monitoring techniques is essential. For the present article, the area selected for study was the monitoring point of CETESB (Environmental Company of the State of São Paulo) - STAN 02700, at the bridge of the Santo Anastácio River, Highway SP 563, being this an area with limnological data availability performed by CETESB, and for being a region with a history of land use and occupation by sugarcane monoculture, receiving also untreated effluents. The study aimed at the comparative analysis of the limnological variables obtained at the monitoring point, in a seasonal manner in the months of February, April, June, August, October and December, from 2015 to 2017, made available by CETESB with the reference values of the CONAMA resolution 357/05, verifying the quality of the water course in question. After the values available by the Company were made available, the parameters (biochemical oxygen demand, dissolved iron, total phosphorus, turbidity and Escherichia Coli) were selected because they present values that are not in conformity with the classification as class 2 river that it receives, regardless of the period studied (2015-2017), values above the acceptable limit due to the influence of monoculture in the region (turbidity), discharge of untreated effluents (BOD, Escherichia Coli, dissolved oxygen, total phosphorus and dissolved iron, the latter may still be altered by the composition of the local soil)

KEY WORDS: Water Resources. Land Use and Occupation. Santo Anastácio River. Limnological Variables.

\section{RESUMEN}

En el preocupante escenario de degradación de los recursos hídricos, es necesario encontrar mecanismos que ayuden a la conservación y recuperación de los entornos naturales degradados, para lo cual es fundamental el uso de técnicas de evaluación y vigilancia ambiental. Para el presente artículo, el área seleccionada para el estudio fue el punto de monitoreo de la CETESB (Compañía Ambiental del Estado de São Paulo) - STAN 02700, en el puente del Río Santo Anastácio, Carretera SP 563, siendo esta un área con disponibilidad de datos limnológicos realizados por la CETESB, y por ser una región con una historia de uso y ocupación de la tierra por el monocultivo de la caña de azúcar, recibiendo también efluentes no tratados. El estudio tuvo como objetivo el análisis comparativo de las variables limnológicas obtenidas en el punto de monitoreo, de manera estacional en los meses de febrero, abril, junio, agosto, octubre y diciembre, de 2015 a 2017, puestas a disposición por el CETESB con los valores de referencia de la resolución 357/05 de la CONAMA, verificando la calidad del curso de agua en cuestión. Después de que se dispusiera de los valores disponibles por la Compañía, se seleccionaron los parámetros (demanda bioquímica de oxígeno, hierro disuelto, fósforo total, turbidez y Escherichia Coli) porque presentan valores que no se ajustan a la clasificación como 
río de clase 2 que recibe, independientemente del período estudiado (2015-2017), valores superiores al límite aceptable debido a la influencia del monocultivo en la región (turbidez), descarga de efluentes no tratados (DBO, Escherichia Coli, oxígeno disuelto, fósforo total y hierro disuelto, este último todavía puede ser alterado por la composición del suelo local)

PALAVRAS CLAVE: Recursos Hídricos. Uso e Ocupacion del Solo. Rio Santo Anastácio. Variables Limnológicas. 


\section{INTRODUÇÃO}

A água é um recurso natural de fundamental importância para o planeta Terra. A sua distribuição nos principais reservatórios é de que $97,5 \%$ do volume total de água da Terra sejam de água salgada, formando os oceanos, e somente $2,5 \%$ seja de água doce. A forma de armazenamento em que os recursos hídricos estão mais acessíveis ao uso humano e de ecossistemas é a água doce contida em lagos e rios, o que corresponde a apenas $0,27 \%$ do volume de água doce da Terra, e cerca de $0,007 \%$ do volume total de água (SETTI et al., 2000). Os recursos hídricos são um dos recursos naturais mais explorados, devido a sua finalidade, com destaque para o abastecimento urbano, geração de energia, navegação, aquicultura, irrigação e a harmonia paisagística (MORAES; JORDÃO, 2002).

Segundo Tundisi (2005), alterações na quantidade, distribuição e qualidade dos recursos hídricos ameaçam a sobrevivência humana e as demais espécies do planeta, estando o desenvolvimento econômico e social dos países fundamentados na disponibilidade de água de boa qualidade e na capacidade de sua conservação e proteção.

As fontes que levam à degradação da qualidade da água podem ser classificadas, segundo a CETESB (2009, apud BUZELLI e SANTINO, 2013) em pontuais, que são aquelas caracterizadas pelos efluentes domésticos e industriais, e em difusas, que são os resíduos provenientes da agricultura (fertilizantes, herbicidas, inseticidas, fungicidas, entre outros) e o escoamento superficial (urbano e rural).

Entende-se por fontes pontuais aquelas fontes de poluição que podem ser identificadas e diagnosticadas, sendo que, em muitos casos, é possível estabelecer ações corretivas ou mesmo punitivas (SODRÊ, 2012). Já por fontes difusas de poluição, também denominadas não pontuais, Sodrê (2012) descreve como sendo aquelas fontes que não é possível monitorar os agentes poluentes a partir do ponto de origem, pois a fonte exata da descarga e os meios de difusão do poluente são extremamente difíceis de identificar.

$\mathrm{O}$ uso e as diversas formas de ocupação do solo pela sociedade contribuem com as alterações das características físico-químicas dos recursos hídricos, mediante a disposição de resíduos orgânicos e compostos químicos resultantes das atividades antrópicas, fazendo com que a qualidade das águas fique comprometida (GONÇALVES; ROCHA e FERREIRA, 2011).

Segundo Paula; Benedetti; Pereira Filho (2016, p. 144), "conhecer a relação entre o uso e a ocupação do solo e a qualidade da água é indispensável para a identificação de principais ameaças à qualidade da água, no intuito de subsidiar a gestão de recursos hídricos".

Com relação aos solos, Boin (2000), relata que os solos da região do Oeste Paulista têm sua gênese de rochas areníticas do Grupo Bauru e de rochas básicas do Grupo São Bento (Serra Geral). Já Rocha (2014) identifica os solos presentes na bacia do Rio Santo Anastácio como sendo Latossolo Vermelho Escuro e Podzólico Vermelho Amarelo, o qual será denominado de Argissolo no texto, conforme a atual nomenclatura dos solos (EMBRAPA, 1999).

O médio curso da bacia do rio Santo Anastácio, área onde está localizado o ponto de monitoramento STAN 02700, apresenta-se de acordo com Fernandes et al. (2018) com extensas áreas de cultivo e plantio de cana- de-açúcar, além de solo exposto, alguns 
remanescentes de vegetação natural e áreas urbanas. Nesse sentido, Sudo (1980), cita que os solos predominantes na bacia do Rio Santo Anastácio apresentam-se como arenosos, com predominância de frações finas a muito finas e apresentam teor de argila inferior a $30 \%$.

$\mathrm{O}$ alto curso da bacia, se refere a região 01, caracteriza-se geomorfologicamente, por colinas amplas e médias e morretes alongados, há um declive mais acentuado nesta porção da bacia. No que diz respeito ao médio curso da bacia, denominada região 02, Gonçalves; Rocha (2011) ressalta que a área possui relevo colinoso, com colinas amplas e médias. Constitui-se em arenitos finos a médios mal selecionados da formação Santo Anastácio, e três tipos de arenitos finos a muito finos da formação Adamantina (arenitos, silitos arenosos e arenitos argilosos). Por fim, o baixo curso da bacia, identificada por região 03 , há o predomínio de um relevo mais tênue e plano, com colinas e planícies aluviais. Geologicamente, conta com as formações Adamantina, Santo Anastácio e Caiuá. No que se refere aos tipos de solos, esta região possui argissolos vermelho-amarelo e latossolo vermelho-escuro (GONÇALVES; ROCHA, 2011).

No que diz respeito ao uso e ocupação do solo na bacia hidrográfica do rio Santo Anastácio, Gonçalves; Rocha; Ferreira (2011) disponibilizam essas informações, através do uso de seis classes temáticas.

A classe temática predominantemente na bacia hidrográfica do rio Santo Anastácio é a pastagem, ocupando aproximadamente $63,8 \%$ da área total da bacia. Contudo, nota-se segundo Gonçalves; Rocha; Ferreira (2011) que a área de estudo está inserida na abertura e implantação de culturas temporárias, como a cana-de-açúcar, que ocupa cerca de $13,72 \%$ da área estudada e insere-se principalmente no médio curso da bacia do rio Santo Anastácio, onde está instalada a usina de álcool e açúcar Decasa.

Com relação à classe temática referente a solo exposto, o gráfico 1 apresenta a quantificação de solo exposto na bacia em aproximadamente $6,02 \%$ no total da área e representa principalmente áreas que estão em estágio de preparo para o plantio da cana-de-açúcar, assim como também em menor quantidade esta classe é expressa por pastagens degradadas, onde a gramínea está altamente espaçada e muito seca, predominando a característica de solo exposto na área (GONÇALVES; ROCHA; FERREIRA, 2011), conforme indicado no gráfico 1

Gráfico 1 - Uso do solo na Bacia Hidrográfica do Rio Santo Anastácio

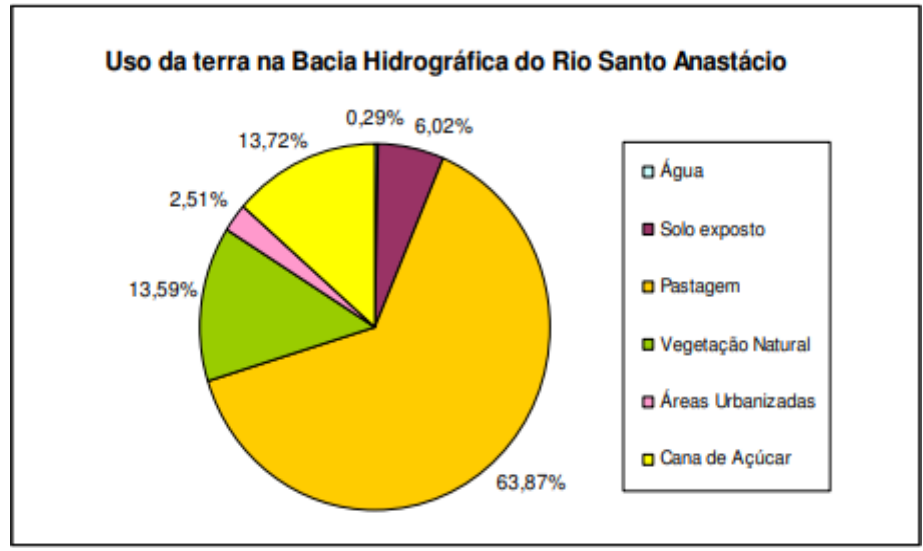

Fonte: GONÇALVES; ROCHA E FERREIRA, 2011. 
A vegetação natural representa $13,59 \%$ da área estudada e a água $0,29 \%$. De acordo com Gonçalves; Rocha; Ferreira (2011), as baixas porcentagens de vegetação na bacia hidrográfica do rio Santo Anastácio é um dado preocupante, visto que, as florestas são unidades importantes que equilibram o ambiente e evitam a degradação do mesmo. Os baixos valores da classe água justificam-se principalmente pela largura do canal. A classe água aparece em maior quantidade na foz rio Santo Anastácio, devido à influência da construção do reservatório da Usina Hidrelétrica Porto Primavera, a qual elevou o nível da água (GONÇALVES; ROCHA; FERREIRA, 2011).

A classe temática áreas urbanizadas aparece em $2,51 \%$ da área e é representada principalmente pelos municípios de Presidente Prudente, Santo Anastácio e Presidente Venceslau (GONÇALVES; ROCHA; FERREIRA, 2011).

Diante de um cenário preocupante da degradação dos recursos hídricos, se faz necessário encontrar mecanismos capazes de auxiliar na conservação e recuperação de ambientes naturais degradados, e para isso a utilização de técnicas de avaliação e monitoramento ambiental, torna- se imprescindível.

De acordo com Rodrigues e Pirrassa (2011) a escolha dos parâmetros a serem analisados, e a variação temporal e espacial podem favorecer a identificação das fontes degradadoras da área de estudo.

O presente estudo baseou-se na análise comparativa dos valores das variáveis limnológicas extraídas das amostras coletadas pela CETESB (Companhia Ambiental do Estado de São Paulo) no rio Santo Anastácio (ponto de monitoramento STAN 02700), entre os anos de 2015 a 2017, no município de Piquerobi - SP, com os valores de referência da resolução CONAMA 357/05 e correlacionando a influência do uso e ocupação do solo nas prováveis causas das variações dos valores, ficando constatado que o processo de uso e ocupação do solo além da falta de tratamento de efluentes em algumas localidades influencia diretamente na qualidade da água.

\section{OBJETIVOS}

$\mathrm{O}$ artigo teve como finalidade a análise comparativa de dados limnológicos disponibilizados pela CETESB, podendo traçar assim um parâmetro de qualidade hídrica no percurso analisado (STAN 02700) do Rio Santo Anastácio, podendo constatar quais são as variáveis em desconformidade com a portaria vigente e apontar causas para essas alterações.

\section{METODOLOGIA}

Para o desenvolvimento do estudo, foram extraídos resultados limnológicos do ponto de monitoramento da CETESB (Companhia Ambiental do Estado de São Paulo) - STAN 02700, na ponte do rio Santo Anastácio, Rodovia SP 563 (que liga Presidente Venceslau/SP a Teodoro Sampaio/SP), município de Piquerobi - SP, cuja coordenadas geográficas são: Latitude Sul 22은 01' 25" - Longitude Oeste 51 53' 27". A Figura 1 apresenta a localização do ponto de monitoramento STAN 02700 no rio Santo Anastácio, no Pontal do Paranapanema. Nesse trecho, o rio está classificado como Classe 2.

O Rio Santo Anastácio, importante afluente do Rio Paraná, nasce no município de Regente Feijó - SP, (22 18' 18” S, 51 26’ 28, 6” W) e deságua na margem esquerda do Rio Paraná, 
próximo ao município de Presidente Epitácio - SP. Seu curso principal apresenta uma extensão de $155 \mathrm{~km}$, onde suas águas são usadas com a finalidade de abastecimento, diluição de esgoto e irrigação agrícola. A

Figura 1: Região do Pontal do Paranapanema e localização do ponto de monitoramento STAN02700 no Rio Santo Anastácio

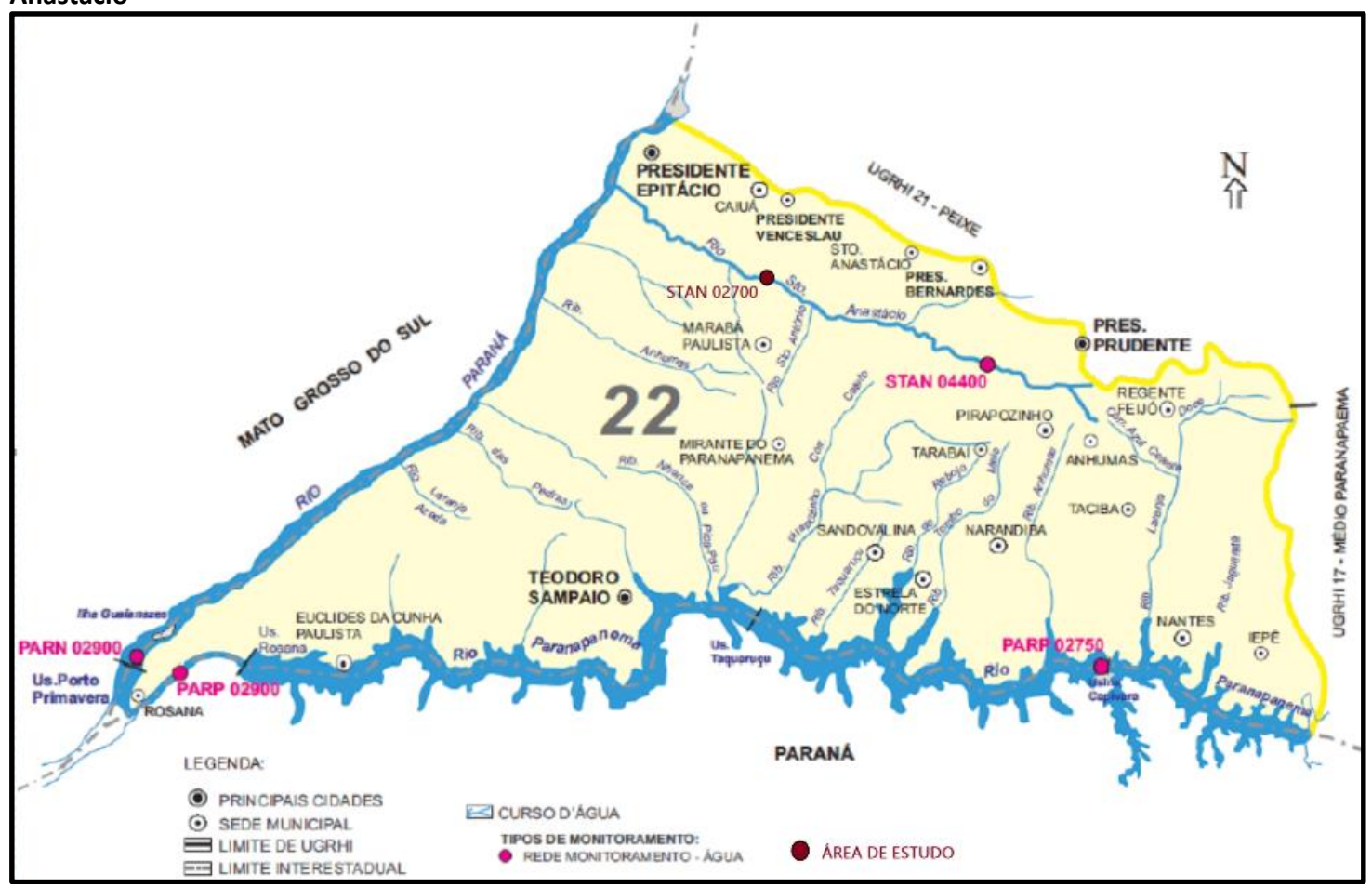

Fonte: CETESB, 2011.

O procedimento de análise foi realizado através de método comparativo, onde todos os parâmetros físicos, químicos e biológicos disponibilizados no banco de dados da CETESB para os anos de 2015, 2016, 2017, foram comparados com os valores de referência da resolução CONAMA 357/05. Após a análise, foram selecionados somente os parâmetros que apresentaram valores em desconformidade, em relação as referências da resolução CONAMA $357 / 05$, para rios de classe 2 .

\section{RESULTADOS}

A Tabela 1 aponta as variáveis em desconformidade para um rio de classe 2, variáveis estas determinadas pela Resolução CONAMA 357/05, destacadas por um *.Código do Ponto: 200 00 SP 22532 STAN 02 700. Sistema Hídrico: Rio Santo Anastácio. Classe 2. Localização: Ponte na rodovia que liga Presidente Venceslau a Teodoro Sampaio, SP 563. - PIQUEROBI - SP 
Tabela 1: Parâmetros químicos, físicos e microbiológicos

\begin{tabular}{|c|c|c|c|c|c|}
\hline \multicolumn{3}{|c|}{ Tipo de Parametro: Físico Químico } & \multicolumn{3}{|c|}{ Análise: Demanda Bioquímica de Oxigênio (mg/L) } \\
\hline \multicolumn{6}{|c|}{ Padrão CONAMA: $<5 \mathrm{mg} / \mathrm{L}$} \\
\hline $\begin{array}{l}\text { Data de } \\
\text { coleta }\end{array}$ & Valor & $\begin{array}{l}\text { Data de } \\
\text { coleta }\end{array}$ & Valor & $\begin{array}{l}\text { Data de } \\
\text { coleta }\end{array}$ & Valor \\
\hline $26 / 02 / 2015$ & $14 *$ & $25 / 02 / 2016$ & 3 & $01 / 02 / 2017$ & 4 \\
\hline $07 / 04 / 2015$ & $7^{*}$ & $12 / 04 / 2016$ & 4 & $27 / 04 / 2017$ & $13 *$ \\
\hline $23 / 06 / 2015$ & $6 *$ & $23 / 06 / 2016$ & 3 & $20 / 06 / 2017$ & $<2$ \\
\hline $25 / 08 / 2015$ & - & $25 / 08 / 2016$ & 4 & $22 / 08 / 2017$ & 4 \\
\hline $14 / 10 / 2015$ & 4 & $04 / 10 / 2016$ & 4 & $05 / 10 / 2017$ & 5 \\
\hline $15 / 12 / 2015$ & 3 & $15 / 12 / 2016$ & 5 & $12 / 12 / 2017$ & 3 \\
\hline \multicolumn{3}{|c|}{ Tipo de Parametro: Físico Químico } & \multicolumn{3}{|c|}{ Análise: Turbidez (UNT) } \\
\hline \multicolumn{6}{|c|}{ Padrão CONAMA: $<100$ UNT } \\
\hline $\begin{array}{c}\text { Data de } \\
\text { coleta }\end{array}$ & Valor & $\begin{array}{c}\text { Data de } \\
\text { coleta }\end{array}$ & Valor & $\begin{array}{c}\text { Data de } \\
\text { coleta }\end{array}$ & Valor \\
\hline $26 / 02 / 2015$ & $118 *$ & $25 / 02 / 2016$ & $413^{*}$ & $01 / 02 / 2017$ & $\begin{array}{c}415 \\
*\end{array}$ \\
\hline 07/04/2015 & 39 & $12 / 04 / 2016$ & 50 & $27 / 04 / 2017$ & $\begin{array}{c}145 \\
*\end{array}$ \\
\hline $23 / 06 / 2015$ & 23 & $23 / 06 / 2016$ & 41 & $20 / 06 / 2017$ & 37 \\
\hline $25 / 08 / 2015$ & 19 & $25 / 08 / 2016$ & 53 & $22 / 08 / 2017$ & 40 \\
\hline $14 / 10 / 2015$ & $174 *$ & $04 / 10 / 2016$ & 24 & $05 / 10 / 2017$ & 58 \\
\hline $15 / 12 / 2015$ & $122^{*}$ & $15 / 12 / 2016$ & $170^{*}$ & $12 / 12 / 2017$ & 46 \\
\hline \multicolumn{3}{|c|}{ Tipo de Parametro: Físico químico } & \multicolumn{3}{|c|}{ Análise: Ferro Dissolvido (mg/L) } \\
\hline \multicolumn{6}{|c|}{ Padrão CONAMA: $<0,3 \mathrm{mg} / \mathrm{L}$} \\
\hline $\begin{array}{l}\text { Data de } \\
\text { coleta }\end{array}$ & Valor & $\begin{array}{l}\text { Data de } \\
\text { coleta }\end{array}$ & Valor & $\begin{array}{l}\text { Data de } \\
\text { coleta }\end{array}$ & Valor \\
\hline $26 / 02 / 2015$ & $0,301^{*}$ & $25 / 02 / 2016$ & 0,116 & $01 / 02 / 2017$ & 0,282 \\
\hline $07 / 04 / 2015$ & - & $12 / 04 / 2016$ & - & $27 / 04 / 2017$ & - \\
\hline $23 / 06 / 2015$ & 0,159 & $23 / 06 / 2016$ & 0,197 & $20 / 06 / 2017$ & $0,426 *$ \\
\hline $25 / 08 / 2015$ & 0,129 & $25 / 08 / 2016$ & 0,172 & $22 / 08 / 2017$ & $0,365 *$ \\
\hline $14 / 10 / 2015$ & - & $04 / 10 / 2016$ & - & $05 / 10 / 2017$ & - \\
\hline $15 / 12 / 2015$ & $0,45^{*}$ & $15 / 12 / 2016$ & $0,656 *$ & $12 / 12 / 2017$ & 0,134 \\
\hline
\end{tabular}




\begin{tabular}{|c|c|c|c|c|c|}
\hline \multicolumn{3}{|c|}{ Tipo de Parametro: Físico químico } & \multicolumn{3}{|c|}{ Análise: Fosforo Total mg/L } \\
\hline \multicolumn{6}{|c|}{ Padrão CONAMA: <0,1 mg/L } \\
\hline $\begin{array}{l}\text { Data de } \\
\text { coleta }\end{array}$ & Valor & $\begin{array}{c}\text { Data de } \\
\text { coleta }\end{array}$ & Valor & $\begin{array}{c}\text { Data de } \\
\text { coleta }\end{array}$ & Valor \\
\hline $26 / 02 / 2015$ & $0,116^{*}$ & $25 / 02 / 2016$ & $0,14 *$ & $01 / 02 / 2017$ & $0,108^{*}$ \\
\hline 07/04/2015 & $0,129 *$ & $12 / 04 / 2016$ & 0,068 & $27 / 04 / 2017$ & $0,255^{*}$ \\
\hline 23/06/2015 & $0,115^{*}$ & $23 / 06 / 2016$ & 0,089 & $20 / 06 / 2017$ & 0,094 \\
\hline $25 / 08 / 2015$ & 0,097 & $25 / 08 / 2016$ & $0,101^{*}$ & $22 / 08 / 2017$ & $0,116^{*}$ \\
\hline $14 / 10 / 2015$ & $0,137^{*}$ & $04 / 10 / 2016$ & $0,114 *$ & $05 / 10 / 2017$ & $0,103^{*}$ \\
\hline $15 / 12 / 2015$ & 0,076 & $15 / 12 / 2016$ & $0,13^{*}$ & $12 / 12 / 2017$ & 0,094 \\
\hline \multicolumn{3}{|c|}{ Tipo de Parametro: Microbiológico } & \multicolumn{3}{|c|}{ Análise: Escherichia coli** (UFC/100 ml) } \\
\hline \multicolumn{6}{|c|}{ Padrão CONAMA: <600 UFC/ $100 \mathrm{ml}$} \\
\hline $\begin{array}{c}\text { Data de } \\
\text { coleta }\end{array}$ & Valor & $\begin{array}{c}\text { Data de } \\
\text { coleta }\end{array}$ & Valor & $\begin{array}{c}\text { Data de } \\
\text { coleta }\end{array}$ & Valor \\
\hline $26 / 02 / 2015$ & $3100 *$ & $25 / 02 / 2016$ & $3400 *$ & $01 / 02 / 2017$ & $9600^{*}$ \\
\hline 07/04/2015 & $620^{*}$ & $12 / 04 / 2016$ & 460 & $27 / 04 / 2017$ & $4500 *$ \\
\hline $23 / 06 / 2015$ & 280 & 23/06/2016 & 220 & 20/06/2017 & $740^{*}$ \\
\hline $25 / 08 / 2015$ & 276 & $25 / 08 / 2016$ & $1300 *$ & $22 / 08 / 2017$ & $1620^{*}$ \\
\hline $14 / 10 / 2015$ & $5200 *$ & $04 / 10 / 2016$ & 180 & 05/10/2017 & $4300^{*}$ \\
\hline 15/12/2015 & $1000^{*}$ & 15/12/2016 & $5800 *$ & $12 / 12 / 2017$ & $720^{*}$ \\
\hline
\end{tabular}

Fonte: RESOLUÇÃO CONAMA 357/05 (ADAPTADA), 2009.

(*) Não atendimento aos padrões de qualidade da Resolução CONAMA 357/05

$\left({ }^{* *}\right)$ Escherichia coli - Padrão de qualidade de acordo com limites estabelecidos na Decisão de Diretoria n 112/2013/E de 09/04/2013, publicada no Diário Oficial do Estado de São Paulo em 13/12/2011.

(-) Valores não detectáveis

$\operatorname{A~DBO}(5,20)$ é um dos parâmetros de maior importância na caracterização dograu de poluição de um corpo d'água (Von Sperling, 2005).

No ano de 2015, foram coletadas cinco amostras, onde três apresentaram valores acima (14 $\mathrm{mg} / \mathrm{L} / 7 \mathrm{mg} / \mathrm{L} / 6 \mathrm{mg} / \mathrm{L}$ ) do estabelecido pela resolução CONAMA 357/05 que é de $<5 \mathrm{mg} / \mathrm{L}$. As coletas foram realizadas respectivamente em fevereiro, no período das chuvas, em abril, no período de transição e em junho, no período de estiagem. Já para o ano 2016, não houve valores fora do padrão CONAMA.

No ano de 2017, das seis amostras coletadas, apenas uma, realizada no mês de abril, no período de transição, apresentou valor superior ( $13 \mathrm{mg} / \mathrm{L}$ ) ao da referência do CONAMA que é de até $<5 \mathrm{mg} / \mathrm{L}$.

Entre os anos de 2015 e 2016, dos oito valores obtidos, apenas três estavam em desconformidade com o padrão estabelecido pela resolução do CONAMA 357/05 que é 
inferior a 0,3 mg/L, sendo todos obtidos em períodos de chuva $(0,301 \mathrm{mg} / \mathrm{L}$ - fev. $15 / 0,45 \mathrm{mg} / \mathrm{L}$ - dez.15 / 0,656 mg/L - dez.16).

De acordo com a CETESB (2014), nas águas superficiais, o nível de ferro aumenta nas estações chuvosas devido ao carreamento de solos e a ocorrência de processos de erosão das margens. Destaca ainda, a importante contribuição dos efluentes industriais, principalmente das indústrias metalúrgicas ao desenvolverem atividades de remoção da camada oxidada (ferrugem) das peças.

Em contrapartida, os valores referentes ao ano de 2017 que se apresentaram acima do valor de referência da resolução CONAMA 357/05, foram obtidos em períodos de estiagem (0,426mg/L- jun.17 / 0,365 mg/L - ago.17).

Segundo Oliveira et al. (2012) o intemperismo das rochas que compõem a bacia de drenagem e a erosão dos solos tem se mostrado responsáveis pelos elevados níveis desse elemento nos corpos d'água.

O fósforo total é necessário ao processo energético de todos os seres vivos, porém se torna prejudicial o seu excesso ou sua escassez, já que o mesmo se faz indispensável aos microrganismos que promovem a oxidação bioquímica do esgoto e favorece o desenvolvimento de algas nos corpos d'água que o recebem (DACACH, 1991).

Segundo Von Sperling (2005), o fósforo é encontrado em corpos d'água em sua forma natural e na sua forma antropogênica, sendo a sua forma natural devido à dissolução de compostos do solo e a decomposição da matéria orgânica. A sua origem antropogênica é devido aos despejos domésticos, industriais, detergentes e excrementos de animais, além do uso de fertilizantes.

A concentração máxima permitida para esta variável em rios de classe 2 de ambientes lóticos deve ser inferior a $0,1 \mathrm{mg} / \mathrm{L}$.

No ano de 2015, das seis amostras que foram analisadas, quatro estavam com os valores acima do estabelecido pela resolução do CONAMA 357/05, sendo $(0,116 \mathrm{mg} / \mathrm{L}$ - fev.15) - período de chuvas, $(0,129 \mathrm{mg} / \mathrm{L}$ - abr.15 e 0,137 mg/L - out..15) - período de transição e $(0,115 \mathrm{mg} / \mathrm{L}$ jun.15) - período de estiagem.

Para o ano de 2016, a quantidade de amostragem realizada e que apresentaram valores fora do padrão CONAMA, foram iguais ao do ano anterior. Sendo as coletadas em fevereiro $(0,147 \mathrm{mg} / \mathrm{L})$, dezembro $(0,13 \mathrm{mg} / \mathrm{L})$

- ambas em período de chuva, agosto $(0,101 \mathrm{mg} / \mathrm{L})$ - período de estiagem e em outubro $(0,114$ $\mathrm{mg} / \mathrm{L}$ ) - período de transição.

No ano de 2017, de um total de seis coletas, quatro $(0,108 \mathrm{mg} / \mathrm{L}$ - fev.17) - período de chuva, $(0,255 \mathrm{mg} / \mathrm{l}$ - abr.17 e 0,103 mg/L - out.17) - período de transição e $(0,116 \mathrm{mg} / \mathrm{L}$ - ago. 17) período de estiagem, apresentaram valores em desconformidade em relação aos valores de referência da resolução CONAMA357/05.

De acordo com Jordão e Pessoa (1995) a turbidez representa o grau de interferência com a passagem da luz através da água, conferindo uma aparência turva à mesma. Geralmente é causada por uma grande variedade de sólidos em suspensão.

O principal causador de turbidez em ambientes lóticos são os sólidos em suspensão, que 
podem ser partículas inorgânicas, como areia, silte e argila, ou partículas orgânicas, como bactérias e algas (CRUZ, 2015).

A erosão das margens dos rios em estações chuvosas, que é intensificada pelo mau uso do solo, é segundo a CETESB (2014) um exemplo de fenômeno que resulta em aumento da turbidez das águas. Ainda, de acordo com a CETESB (2014) os esgotos domésticos, diversos efluentes industriais e a atividade mineradora também provocam elevações na turbidez das águas.

No ano de 2015, das seis amostras coletadas, três apresentaram valores superiores (118 UNT, 174 UNTe 122 UNT) ao valor de referência da resolução do CONAMA 357/05 que é de $<100$ UNT. Tendo as amostras com os valores em desconformidade sido coletadas em fevereiro (período de chuvas), outubro (período de transição) e dezembro de 2015 (período de chuva). Para o ano de 2016, foram realizadas seis amostragens, sendo que duas apresentaram valores acima (415 UNT e 170 UNT) do padrão CONAMA. Ambas as amostragens, foram realizadas no período das chuvas.

Dentre as seis coletas realizadas no ano de 2017, duas estão com seus valores (415UNT e 145UNT) em desconformidade com a resolução CONAMA. Sendo uma realizada no período das chuvas e outra no período de transição.

No ponto de monitoramento STAN 02700, do Rio Santo Anastácio, essa variável vem apresentando valores discrepantes ao ser comparado com os valores de referência da resolução CONAMA 357/05, há muitos anos. Segundo a Agência Nacional das Águas (2014) em 2012 nesse ponto de monitoramento a turbidez apresentou valores elevados, ultrapassando o limite especificado na resolução do CONAMA.

A Escherichia Coli faz parte da microbiota intestinal do homem e de outros animais de sangue quente. Quando detectados em uma amostra de água fornecem evidência direta de contaminação fecal recente, e por sua vez podem indicar a presença de patógenos entéricos (CUNHA, et al., 2012).

No ano de 2015, seis amostras foram analisadas, sendo que quatro estavam fora do padrão estabelecido pelo CONAMA, tendo sido realizadas em fevereiro $(3100 \mathrm{UFC} / 100 \mathrm{ml}$ ) e dezembro (1000 UFC/100ml) -período de chuvas e abril (620 UFC/100 ml) e outubro (5200 UFC/100ml - período de transição.

Para o ano de 2016, foram realizadas a mesma quantidade de amostragens do ano anterior, porém, três valores encontravam-se em desconformidade com a resolução do CONAMA, onde foram obtidos em fevereiro (3400 UFC/100ml) e dezembro (5800 UFC/100ml) - período das chuvas e agosto (1300 UFC/100ml) - período de estiagem.

No ano de 2017, todas as seis amostragens analisadas apresentaram os valores acima (9600 UFC/100ml / 720 UFC/100ml / 4500 UFC/100ml / 4300 UFC/100ml / 740 UFC/100 ml / 1620 UFC/100ml) da referência determinada pela resolução Conama 357/05, independentemente do período do ano que foram realizadas as coletas.

Deve ser salientado ainda, de acordo com Silva (2006) que o Rio Santo Anastácio e seus afluentes encontram-se completamente poluído por esgotos de origem doméstica das cidades de Presidente Prudente, Presidente Venceslau e Álvares Machado que vem causando sérios 
danos ambientais em seu ambiente aquáticos. Ressalta ainda, que recebe também águas residuárias (carga orgânica remanescente) de atividades de abate de bovinos e de laticínios e curtumes, que vem degradando cada vez mais a qualidade das águas do rio.

\section{CONCLUSÃO}

De acordo com a análise de dados da CETESB realizada entre os anos de 2015 à 2017 tendo como referencia a resolução CONAMA 357/05 e correlacionando ao estudo de uso e ocupação do solo, ficou verificado que variáveis limnológicas importantes para um rio enquadrado como sendo de classe 2 não estavam dentro dos padrões estabelecidos pela resolução pertinente. Alterações estas provocadas pela monocultura de cana de açúcar presente na região, solo desprovido de vegetação em muitas áreas e despejo de efluentes sem tratamento. $O$ conjunto de fatores apresentados e os resultados limnológicos obtidos indicam que o rio sofre um processo de contaminação e degradação preocupante, uma vez que é um importante afluente do Rio Paraná.

\section{REFERÊNCIAS BIBLIOGRÁFICAS}

Agência Nacional de Águas (ANA). Portal da Qualidade das Águas - Indicadores de Qualidade - Índice de Qualidade das Águas (IQA). Brasília DF: Disponível em: <http://portalpnqa.ana.gov.br/indicadores-indice- aguas.aspx>. Acesso em: 13 ago. 2019.

Agência Nacional de Águas (ANA). UGRH PARANAPANEMA - Qualidade da Água. Brasília - DF, 2014.

BARRIOS, N. A. Z., SANT'ANNA NETO, J. L. A circulação atmosférica no extremo oeste paulista. Boletim climatológico, Presidente Prudente, v.1, n.1, p.8-9, março 1996.

BEYRUTH, Z. Comunidade fitoplanctônica da represa de Guarapiranga: 1991-92. Aspectos ecológicos, sanitários e subsídios para reabilitação da qualidade ambiental. 276 f. Tese (Doutorado) - Faculdade de Saúde Pública, Universidade de São Paulo, São Paulo, 1996

BOIN, M. N. Chuvas e erosões no Oeste Paulista: uma análise climatológica aplicada. 2000. 264 f. Tese (Doutorado em Geociências e Meio Ambiente) - Instituto de Geociências e Ciências Exatas, Universidade Estadual Paulista, Rio Claro.

BUZELLI, Giovana Moreti; SANTINO, Marcela Bianchessi da Cunha. Análise e diagnóstico da qualidade da água e estado trófico do reservatório de Barra Bonita - SP. Revista Ambiente \& Água, v. 8, n. 1, p. 186-205, 2013.

CARVALHO, W. A. (coord.) Levantamento Semidetalhado dos solos da Bacia do Rio Santo Anastácio - SP. Boletim Científico no 2 vol. 1. Faculdade de Ciências e Tecnologia/Unesp, Presidente Prudente: 1997

COMPANHIA AMBIENTAL DO ESTADO DE SÃO PAULO (CETESB). Relatório de Qualidade das Àguas Interiores do Estado de São Paulo. 2010

COMPANHIA AMBIENTAL DO ESTADO DE SÃO PAULO (CETESB). Qualidade das águas superficiais do estado de São Paulo - 2014, São Paulo: CETESB. 2015.

COMPANHIA AMBIENTAL DO ESTADO DE SÃO PAULO (CETESB).

Significado ambiental e sanitário das variáveis de qualidade das águas superficiais do estado de São Paulo. Apêndice D. São Paulo: CETESB. 2014.

CONSELHO NACIONAL DO MEIO AMBIENTE (CONAMA). Resolução no357 de março de 2005. Dispõe sobre a 
classificação dos corpos de água e diretrizes ambientais para o seu enquadramento, bem como estabelece as condições e padrões de lançamento de efluentes, e dá outras providências. Diário Oficial da União, Brasília - DF, 18 mar. 2005. no 053, p. 58-63 Disponível em:.

<http://www2.mma.gov.br/port/conama/legiabre.cfm?codlegi=459>Acesso em: 15 ago. 2019.

CRUZ, Natália Ribeiro. Avaliação da qualidade da água em ambientes lóticos do estado de São Paulo: uso e ocupação do solo e sazonalidade. Trabalho de Conclusão de Curso (Monografia) - Graduação em Engenharia Ambiental - USP, São Carlos, 2015. 141p.

CUNHA, H. F. A. et al. Qualidade físico-química e microbiológica de água mineral e padrões da legislação. Revista Ambiente \& Água, v.7, n.3, p. 155-165, 2012.

DACACH, Nelson Gandur. Tratamento primário de esgoto. 1 ed. Rio de Janeiro: EDC - Ed. Didática e Científica, p. 160, 1991.

DRUMOND, Sheila Neves et al. Identificação molecular de Escherichia Coli diarreiogênica na Bacia Hidrográfica do Rio Xopotó na região do Alto Rio Doce. Engenharia Sanitária e Ambiental. v. 23, n. 3, p. 579 - 590, 2018.

FERNANDES, M.R., ARAUJO, R.R., RIZK, M.C., SANTOS, A. A., ROCHA, P.C. Análise limnológica e a expansão da canade-açúcar em uma sub-bacia hidrográfica do rio Santo Anástácio - Piquerobi - SP. In: 3ำ Congresso Internacional de Pesquisa, Ensino e Extensão - CIPEEX: "Ciência para a redução das desigualdades". Anais..., Curitiba: CIPEEX, 2018.

GONÇALVES, Franciele; ROCHA, Paulo Cesar; FERREIRA, Cesar Cardoso. Uso e ocupação da terra e suas influências em parâmetros químicos e físicos da água da bacia hidrográfica do rio Santo Anastácio, Oeste Paulista.

In: XV Simpósio Brasileiro de Sensoriamento Remoto - SBSR, Anais..., Curitiba: INPE, 2011, Artigos, p. 1248 - 1255. Disponível em:

<http://marte.sid.inpe.br/col/dpi.inpe.br/marte/2011/07.08.12.08/doc/p1413.pdf> Acesso em: 15 ago. 2019.

GONÇALVES, Franciele; ROCHA, Paulo Cesar. Influência do meio físico em variáveis limnológicas no rio Santo Anastácio, oeste paulista.

In: IX Encontro Nacional da ANPEGE (Associação Nacional de Pós-Graduação e Pesquisa em Geografia): “A Pesquisa e a Produção Geográficas: o Pulsar no Tempo e no Espaço". Anais..., Goiânia: AMPEGE, 2011

JORDÂO, E. P.; PESSOA, C. A. Tratamento de esgotos domésticos. $3^{\circ}$ ed. Rio de Janeiro: ABES, 1995.

MATO GROSSO. Relatório de monitoramento da qualidade das águas da sub bacia do rio Cuiabá. Cuiabá - MT, 2006. Disponível em:<www.sema.mt;gov.br. Acesso em: 24 ago 2019.

MORAES, D. S. de L.; JORDÃO, B. Q. Degradação de recursos hídricos e seus efeitos sobre a saúde humana. Revista Saúde Pública, Corumbá, v. 36, n.3, p. 370-374, 2002

OLIVEIRA FILHO, P. C. D; DUTRA, A. M.; CERUTI, F. C. Qualidade das águas superficiais e o uso da terra: estudo de caso pontual em bacia hidrográfica do oeste do Paraná. Revista Floresta e Ambiente. v. 19, n. 1, p. 32 - 43. 2012.

PAULA, Makele Rosa de; BENEDETTI, Ana Caroline Paim; FILHO, Waterloo Pereira. Influência do uso e cobertura da terra aliado a precipitação pluviométrica na qualidade da água da bacia hidrográfica do Rio Ingaí - RS - Brasil. Revista do Departamento de Geografia da Universidade de São Paulo, v. 32, s.n., p. 143-152, 2016.

RIBEIRO, W. C. Geografia Política da Água. São Paulo: Editora Annablume, 2008.

ROCHA, P. C. Análise integrada da Variação espacial do transporte de sedimentos no rio Santo Anastácio, Oeste Paulista. Revista Geonorte, v. 10, n. 1, p. 94-98,2014.

RODRIGUÊS, F. M.; PISSARRA, T. C. T. Monitoramento hidrológico de uma bacia hidrográfica com diferentes usos do solo na região de Taquaritinga, Estado de São Paulo. In: SIMPÓSIO BRASILEIRO DE RECURSOS HíDRICOS, 17. 2007, São Paulo. São Paulo: SBRH,2007. 
SILVA, José Augusto da.Gestão de recursos hídricos e sistemas de informações geográficas: contribuições para a organização sócio- espacial do Pontal do Paranapanema-SP. Tese (doutorado) - UNESP, Fac. Ciências e Tecnologia, Pres. Prudente, 2006. 200p.

SODRÉ, Fernando Fabriz. Fontes difusas de poluição da água: características e métodos de controle. Brasília: AQQUA, 2012

SUDO, H. Bacia do Alto Santo Anastácio: estudo geomorfológico. 235f. 1980. Tese (doutorado em Geografia). Departamento de Geografia da FFLCH, Universidade de São Paulo, SãoPaulo.

TOMASONI, M. A., PINTO, J. E. S., SILVA, H. P. A. A questão dos recursos hídricos e as perspectivas para o Brasil. GeoTextos, v. 5, n. 2, p. 107-127, 2009.

TUNDISI, J.G. \& MATSUMURA-TUNDISI, T. Limnologia. Oficina de Textos, 2008. 632p.

VON SPERLING, Marcos. Introdução à qualidade das águas e ao tratamento de esgotos. Departamento de Engenharia Sanitária e Ambiental/UFMG, Belo Horizonte, 1996. 243 p.

ZALIDIS, G.; STAMATIADIS, S.; TAKAVAKOGLOU, V.; ESKRIDGE, K.; MISOPOLINOS, N. Impacts of agricultural practices on soil and water quality in the Mediterranean region and proposed assessment methodology. Agriculture, Ecosystems and Environment, v. 88, p. 137-146, 2002. 